\title{
THE UNIFIED LEVELLING NETWORK OF SARAWAK AND ITS ADJUSTMENT
}

\author{
Z A M Som a , A M Yazid ${ }^{\mathrm{a}}$, T K Ming ${ }^{\mathrm{b}}$, N M Yazid ${ }^{\mathrm{a}}$ * \\ ${ }^{\mathrm{a}}$ GNSS \& Geodynamic Research Group, Universiti Teknologi Malaysia, Johor Bahru, Malaysia \\ ${ }^{\mathrm{b}}$ Topography Section, Department of Surveying \& Mapping, Kuching, Sarawak \\ Correspondence: zainalabidin@utm.my
}

KEY WORDS: Sarawak precise levelling network, least-squares adjustment, MoreFix levelling adjustment package

\begin{abstract}
:
The height reference network of Sarawak has seen major improvement in over the past two decades. The most significant improvement was the establishment of extended precise leveling network of which is now able to connect all three major datum points at Pulau Lakei, Original and Bintulu. Datum by following the major accessible routes across Sarawak. This means the leveling network in Sarawak has now been inter-connected and unified. By having such a unified network leads to the possibility of having a common single least squares adjustment been performed for the first time. The least squares adjustment of this unified levelling network was attempted in order to compute the height of all Bench Marks established in the entire levelling network. The adjustment was done by using MoreFix levelling adjustment package developed at FGHT UTM. The computational procedure adopted is linear parametric adjustment by minimum constraint. Since Sarawak has three separate datums therefore three separate adjustments were implemented by utilizing datum at Pulau Lakei, Original Miri and Bintulu Datum respectively. Results of the MoreFix unified adjustment agreed very well with adjustment repeated using Starnet. Further the results were compared with solution given by Jupem and they are in good agreement as well. The difference in height analysed were within $10 \mathrm{~mm}$ for the case of minimum constraint at Pulau Lakei datum and with much better agreement in the case of Original Miri Datum.
\end{abstract}

\section{INTRODUCTION}

\subsection{Background}

The establishment and maintenance of height reference network has always been the tasks entrusted to surveying authority of any country. This is been the case because height network is part of an important nation infrastructures and been used as reference for mapping and engineering development projects development projects.

Up till now, the height references in many countries were established mainly by precise levelling. It is so because of easiness in implementation since the working procedures of precise levelling are rightly well understood by many. The works required might be laborious and time consuming but the accuracy achieved suit very well with the requirement needed.

The next big task after the completion of the measurement campaign of precise levelling is the task of performing the least squares adjustment. The adjustment is required in order to compute the height of all bench marks established in such network.

The height reference network of Sarawak has seen major improvement in over the past two decades. The most significant improvement was the establishment of the extended precise levelling network of which are now connecting all three major datum points at Pulau Lakei, Original Miri Datum and Bintulu Datum. The development of connecting all three datums was made possible by having a levelling network following the major accessible routes across Sarawak. This means the levelling network in Sarawak has now been inter-connected and unified. By having such a unified network leads to the possibility of implementing a common single least squares adjustment been performed for the first time for the entire levelling network of Sarawak.

This paper is aim at describing the effort of implementing the adjustment of the unified precise levelling network of Sarawak.

\section{THE DEVELOPMENT OF SARAWAK LEVELLING NETWORK}

\subsection{The early development of levelling network of Sarawak}

The Topographic Section of the Department of Survey and Mapping Sarawak (or in Malay is referred to as JUPEM Sarawak) was established in 1989 and among its early tasks was to look after the levelling network of Sarawak. Prior to that, the levelling network in Sarawak was handled by Jabatan Tanah \& Survei Sarawak (JTS).

JTS has made effort establishing precise levelling network in Sarawak beginning way back in 1958 . Due to the vast size of Sarawak and limited accessibility the height network during that early period was concentrated at three zones each using separate datum point. The three height datum points used were Pulau Lakei near Kuching, Original Datum in Miri and Bintulu Datum at Bintulu. Ever since JUPEM Sarawak took over the handling of Sarawak height network a series of improvement have been initiated. It began with the work on second class precise 
levelling to extend the existing height network in order to provide sufficient vertical control particularly to cater the development at big towns like Kuching and Sibu.

The work of extending the first class precise leveling of Sarawak by JUPEM began in 1998. The work was initially concentrating with new leveling line established started from a tide gauge station at Miri (STAPS Miri) and proceeded to Lutong and Simpang Bekenu (Muhamad Asrul 2005). The extent of this early levelling network is shown in Figure 1.

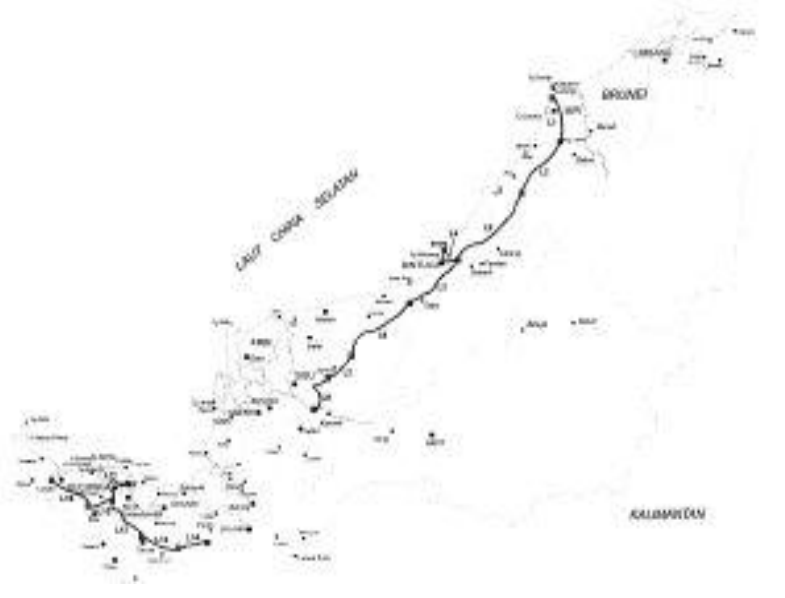

Figure 1. Levelling network established around Kuching and Miri-Sibu

\subsection{The development of extended levelling network up to 2002}

The effort of extending the precise levelling network by Jupem was keep continuing for about five years since it initial involvement in 1998.

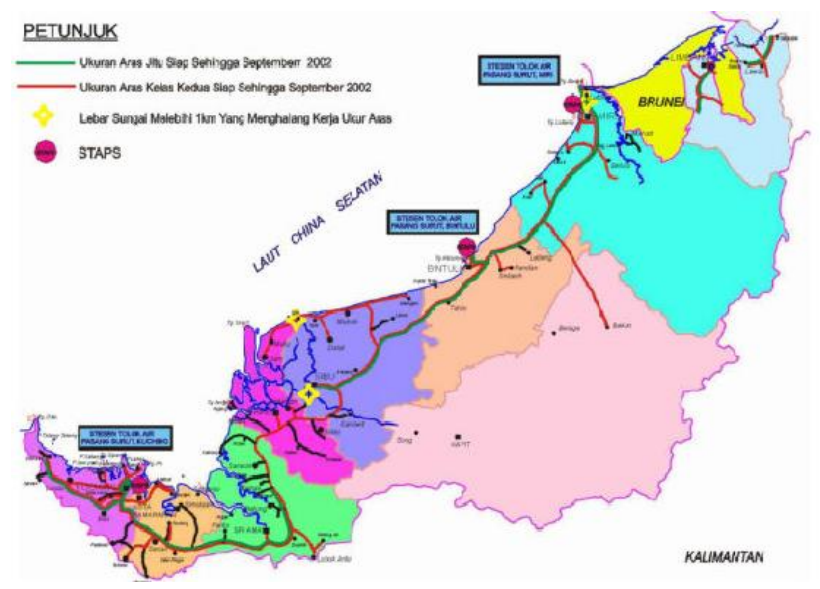

Figure 2. Precise levelling routes of Sarawak as at 2002 (Source - Muhamad Asrul 2006)

By September 2002 JUPEM has reported completing the survey of nineteen leveling loops mainly covering two major areas i.e., Kuching and Miri-Sibu zones as shown in Figure 2.

\subsection{The development of unified levelling network of Sarawak}

Then by mid-2006 another major milestone was achieved by JUPEM with regard to precise levelling network in Sarawak In this period for the first time ever JUPEM has managed in unifying Sarawak leveling network by having a series of precise levelling lines inter connected to all three datum points Pulau Lakei, Bintulu Datum and Original Datum at Miri. This major development was made possible with the completion of three strategic bridges i.e, Lanang Bridge and Durin Bridge (both in Sibu) and Batang Kayan Bridge in Lundu.

By 2008 JUPEM has completed compiling all the observation data covering all the leveling lines and loops. These data has been made available to us at Universiti Teknologi Malaysia (UTM) for the purpose of least squares adjustment computation in order to obtain the height of all BM covered by the unified precise leveling lines in Sarawak. The extent of unified precise leveling lines of Sarawak is shown in Figure 3.

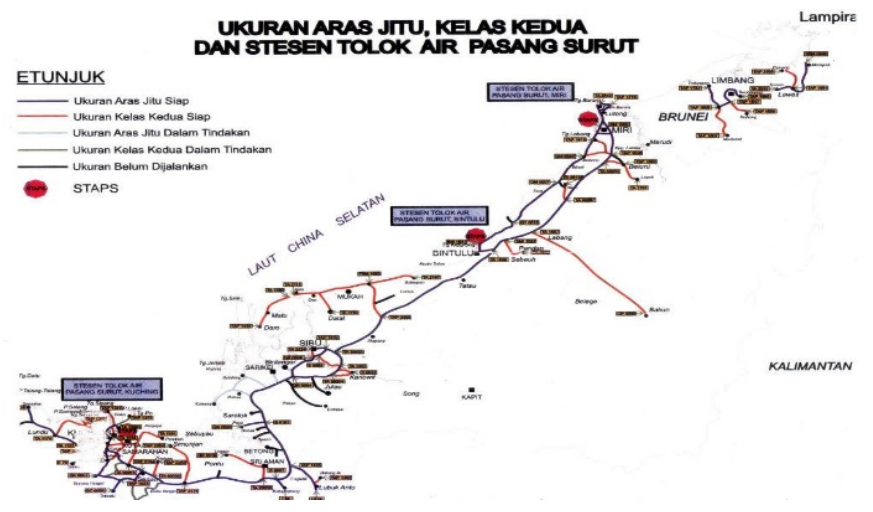

Figure 3. The unified precise leveling lines of Sarawak

\section{THE ADJUSTMENT OF THE UNIFIED LEVELLING NETWORK OF SARAWAK}

The discussion in this section is to highlight the implementation of least squares adjustment of the unified levelling network of Sarawak utilizing the observation data provided by Jupem Sarawak.

\subsection{The adjustment unknown parameter and observation data}

The least squares adjustment of this unified levelling network of Sarawak involves the determination of height of a total of 1408 Bench Marks (BMs) which include the three datum points. The datum points are represented by Bench Mark TA10001 (for Pulau Lakei Datum), BM1000 as Original Datum of Miri and BM1641 for Bintulu Datum. JUPEM record stated that the heights of these datum points as $3.33440 \mathrm{~m}$ (TA10001), 1.24520 (BM1000) and 3.7453m at BM1641.

So in the least squares adjustment by minimum constraint the total number of parameters become 1407 BMs height with the height of one datum point held fixed. The total number of observation data available are 2721. These data consist of height difference compiles from a total of forty five levelling routes as mentioned in JUPEM Report (2008). This means in 
the least squares adjustment for this unified levelling network for Sarawak the A-matrix is having a dimension of 2721 x 1407 and the weight matrix $\mathrm{P}$ is having dimension of $2721 \times 2721$.

The least-squares adjustment computation for the unified precise levelling lines of Sarawak was performed using a selfdeveloped levelling adjustment package named MoreFix. This computational package was developed in-house at UTM and written fully in Fortran and can be run using Microsoft PowerStation 4.0 compiler.

All the observation data were taken from JUPEM's work files which were originally arranged according to Move3 adjustment package format as shown in Fig. 4.

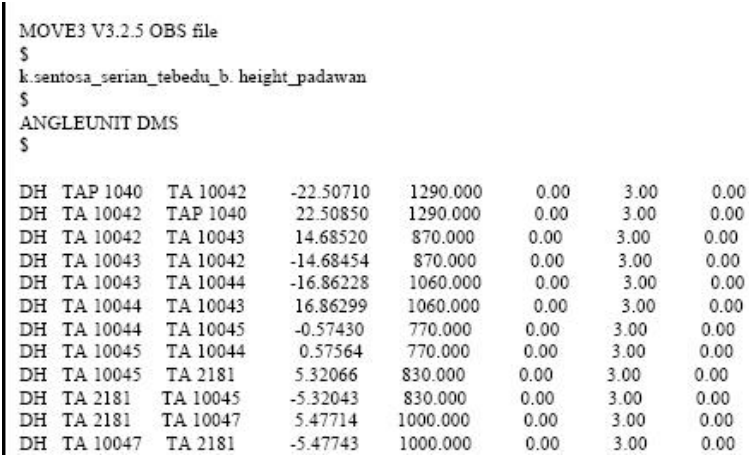

Figure 4. Sample of JUPEM's data in MOVE3 format

Then for the implementation of adjustment using MoreFix the above data input file were re-formatted. The input file format of MoreFix is shown in Figure 5. It follow much the same way as in the last exercise of the adjustment involving Kuching and Miri levelling lines (Zainal Abidin \& Annual 2006).

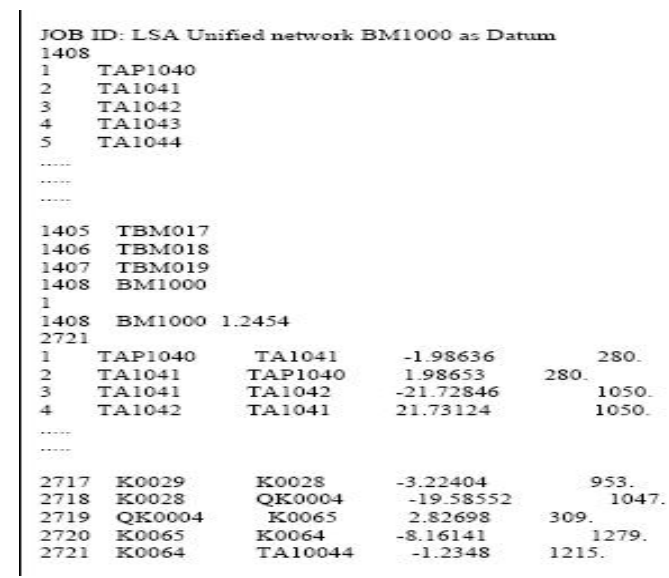

Figure 5. Sample of MoreFix input file format

All the input data information then re-typed to suit the format used by MoreFix which should contain the following;

Job title; the total number of $\mathrm{BM}$; list of all the $\mathrm{BM}$; information on datum point and its height; total number of observation data; and list of observation data. An example of MoreFix input file format is shown in Figure.5.

\subsection{The adjustment by minimum constraint}

The least-squares adjustment by minimum constraint of the unified levelling network of Sarawak using MoreFix was implemented in three separate cases each with different datum point used respectively;

Case A - TA10001 is fixed at 3.3340m (Pulau Lakei datum)

Case B - BM1000 is fixed at 1.24520m (Original Datum Miri)

Case C - BM1641 is fixed at 3.7453 (Bintulu Datum)

The reason of doing the adjustment in three separate cases with using different datum points respectively is to follow the past practice of Jupem. At Jupem presently three set of adjustment results of BM heights available. Each of them was computed separately to accord the three different regions. The levelling lines around Kuching was computed based on Pulau Lakei datum while in the central region it was computed using Original Datum in Miri and those levelling lines in the upper zone of Sarawak was based on Bintulu Datum.

In subsequence to the adjustment computed using MoreFix, the above adjustments were repeated by using commercial package Starnet for checking purposes.

\section{THE ADJUSTMENT RESULTS OF THE UNIFIED LEVELLING NETWORK OF SARAWAK}

The discussion in this section is to highlight the results obtained by the implementation of least squares adjustment of the unified levelling network of Sarawak. The discussion is focussed on two important analysis;

a) results of the adjustment by minimum constraint using three different datums and

b) to compare the result of BM height obtained by unified adjustment with the height from previous adjustment by Jupem.

\subsection{Results of the unified adjustment by minimum constraint}

The adjustments of unified levelling network of Sarawak as described above were successfully completed. Results of the adjustment by MoreFix has provided the height of all BMs (a total $1407 \mathrm{BMs}$ ). Results of minimum constraint adjustment using using datum point TA1258/TA10001 (Pulau Lakei Datum) is shown in Table 1.

Since the complete results were in a very long list therefore height of only twelve BM points were shown in Table 1 as example.

\begin{tabular}{|c|c|c|c|c|}
\hline No & Benchmark & $\begin{array}{c}\text { MoreFix } \\
\text { Result (m) }\end{array}$ & $\begin{array}{c}\text { StarNet } \\
\text { Result (m) }\end{array}$ & $\begin{array}{c}\text { Differences } \\
\text { (m) }\end{array}$ \\
\hline 1 & $\begin{array}{l}\text { TA1258 / } \\
\text { TA10001 } \\
\end{array}$ & 3.33440 & 3.3344 & 0.00000 \\
\hline 2 & TAP1040 & 36.15478 & 36.1548 & -0.00002 \\
\hline 3 & TA1041 & 34.16835 & 34.1684 & -0.00005 \\
\hline 4 & TA1042 & 12.43864 & 12.4387 & -0.00006 \\
\hline 5 & TA1043 & 6.13043 & 6.1305 & -0.00007 \\
\hline 6 & TA1044 & 4.21365 & 4.2137 & -0.00005 \\
\hline 7 & BM1068 & 3.58883 & 3.5889 & -0.00007 \\
\hline 8 & TA1045 & 7.06200 & 7.0621 & -0.00010 \\
\hline 9 & BM1069 & 12.60391 & 12.6041 & -0.00019 \\
\hline 10 & TA1046 & 12.83245 & 12.8326 & -0.00015 \\
\hline 11 & TA1047 & 10.98154 & 10.9817 & -0.00016 \\
\hline 12 & TA1048 & 3.87029 & 3.8704 & -0.00011 \\
\hline
\end{tabular}

Table 1: The results of BMs height computed by MoreFix using Pulau Lakei as datum (Adjustment case A) 
Effort has also been done to repeat the whole adjustment by Starnet computational package using the same input data. The purpose of repeating this adjustment is as a checking to compare the height resulted from both adjustments. The heights obtained from Starnet were shown also in Table 1. Both results are in very good agreement.

With the completion of this adjustment and some results shown in Table 1, the first adjustment of the unified levelling network of Sarawak was successfully achieved. The next task is to analyse the results of this unified adjustment and to compare them with existing height of the same BM (i.e., results of previous adjustment done by Jupem).

\subsection{Comparison of height results obtained from unified adjustment with height from previous adjustment by Jupem}

As mentioned earlier, previously the levelling networks in Sarawak were consist of three separate networks at three different zones (i.e, Kuching, Miri and Bintulu). The adjustment to each of this network was also computed separately using different datum as minimum constraint. The adjustment by Jupem were done using MOVE3 adjustment package.

Information on heights of all BMs from previous adjustment computed by Jupem were available and the record were shared to us at UTM. We used the results of this previous adjustment to compare them with the results of unified adjustment reported here.

Since there were three sets of datum used by Jupem in their adjustment the comparison of MoreFix vs MOVE3 need to be done carefully by choosing the correct set of adjustment results in accordance to each datum respectively (i.e., Case A, B and C).

For example for unified adjustment case A (i.e, datum Pulau Lakei) the comparison is made using BM heights computed by Jupem using the same datum as minimum constraint. Results of these comparison is as shown in Table 2.

\begin{tabular}{|c|c|c|c|c|}
\hline \multirow{2}{*}{ No } & \multirow{2}{*}{ Benchmark } & \multicolumn{2}{|c|}{ Adjusted Height (m) } & \multirow{2}{*}{ 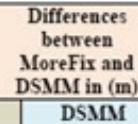 } \\
\hline & & MoreFix & DSMM & \\
\hline 1 & TA1258 & 3.33440 & 3.3344 & $\begin{array}{ll} & 0.0000\end{array}$ \\
\hline 177 & BM320 & 2.68049 & 2.6805 & 0.0000 \\
\hline 188 & BMS96 & 19.81836 & 19.8179 & 0.0005 \\
\hline 190 & BM597 & 21.09340 & 21.0928 & 0.0006 \\
\hline 402 & BM1147 & 26.32229 & 26.3333 & -0.0110 \\
\hline 1010 & BM1463 & 27.51649 & 27.5275 & .0 .0110 \\
\hline 1045 & BM1442 & 62.69537 & 62.7064 & -0.0110 \\
\hline 1096 & BM1415 & 34.60116 & 34.6122 & -0.0110 \\
\hline 1164 & BM1373 & 20.2428 & 20.2528 & -0.0100 \\
\hline 1222 & BM1631 & 11.39631 & 11.4073 & .0 .0109 \\
\hline
\end{tabular}

Table 2: The results of BMs height computed by MoreFix vs Jupem results - Datum Pulau Lakei

(Source - Abdul Muiz, 2015)

The first column in Table 2 (i.e., No) represent the number according to listing arrangement of a particular BM extracted from results output of MoreFix. Please note that there are 1407 unknown parameters involved in the adjustment. Hence in Table 2 no 1 refers to BM TA 1258 which appeared as unknown number one, and unknown no 177 refers to BM320 (which in output listing appeared as unknown number 177) and so on.
So it can be seen from Table 2 that the difference of the BMs height obtained from unified adjustment compared to results computed by Jupem are within $10 \mathrm{~mm}$ (all in negative values).

Table 3 below shows the comparison result of unified adjustment case B (minimum constraint using Datum Original Miri). It can be seen different set of Bench Mark were used in this comparison. This is due to the fact that the distribution of the BMs for case B were covering Miri zone (compares to case A whereby the BMs are around Kuching).

\begin{tabular}{|c|c|c|c|c|}
\hline \multirow{2}{*}{ No } & \multirow{2}{*}{ Benchmark } & \multicolumn{2}{|c|}{ Adjusted Height (m) } & \multirow{2}{*}{$\begin{array}{c}\begin{array}{c}\text { Differences } \\
\text { between } \\
\text { MoreFix and } \\
\text { DSMM in (m) }\end{array} \\
\text { DSMM Original }\end{array}$} \\
\hline & & MoreFix & DSMM Original & \\
\hline 981 & BM831 & 12.1942 & 12.1941 & 0.0001 \\
\hline 968 & BM838 & 39.8596 & 39.8596 & 0.0000 \\
\hline 961 & BM961 & 28.4175 & 28.4175 & 0.0000 \\
\hline 911 & BM992 & 14.2082 & 14.2082 & 0.0000 \\
\hline 851 & BM1040 & 23.9659 & 23.9659 & 0.0000 \\
\hline 840 & BM1046 & 29.3852 & 29.3852 & 0.0000 \\
\hline 833 & BM1050 & 18.6242 & 18.6242 & 0.0000 \\
\hline 822 & BM1057 & 20.8853 & 20.8853 & 0.0000 \\
\hline 813 & BM1062 & 16.5514 & 16.5514 & 0.0000 \\
\hline
\end{tabular}

Table 3: The results of BMs height computed by MoreFix vs Jupem results - Datum Original Miri

(Source - Abdul Muiz, 2015)

It can be seen from Table 3 that the height of BM obtained by unified adjustment agree very much with the results of previous adjustment by Jupem.

In this paper only these two cases of unified adjustment were highlighted and compared (minimum constraint case A and case B). By comparison the unified adjustment case A indicates difference in height around $10 \mathrm{~mm}$ while the adjustment of case $\mathrm{B}$ is in very good agreement with results of previous adjustment.

\section{CONCLUSION \& RECOMMENDATION}

This paper has described about the development of unified levelling network of Sarawak by Jupem. This is a very significant achievement in the establishment of Sarawak reference network for heighting. The unified levelling network succeed in connecting all three height datums used in Sarawak for the first time.

The task of performing the least-squares adjustment of the Sarawak unified levelling network has been successfully done. The adjustment was implemented by MoreFix computation routine to compute height of $1407 \mathrm{BMs}$ using observation data supplied by Jupem.

Results of the MoreFix adjustment agreed very well with adjustment repeated using Starnet. Further the results were compared with solution given by Jupem and they are in good agreement as well. The difference in height analysed were within $10 \mathrm{~mm}$ for the case of minimum constraint at Pulau Lakei datum and with much better agreement in the case of Original Miri Datum.

A future work to assess the most suitable datum among the three currently being used (i.e., Pulau Lakei, Miri and Bintulu) 
is highly recommended. The assessment can be implemented using the currently available data such as the East Malaysia Geoid Model from Jupem, In addition gravity field data from the most recent Global Geopotential Model from GOCE mission is also recommended.

\section{ACKNOWLEDGEMENTS}

The work in this research was partly supported by fund receives from the UTM RU Research Grant (reference no PY/2015/05072). The authors would like to acknowledge this financial support.

We wish to acknowledge the Topography Section of Jupem Sarawak for providing precise levelling data and other related data used in this work.

\section{REFERENCES}

Abdul Muiz Yazid., 2015, “The adjustment of precise levelling network for Sarawak Region “ B. Geom Thesis, UTM Skudai, June 2015

JUPEM Sarawak, 2008. Unpublished Report by Topography Section, JUPEM Sarawak.

Mohamad Asrul Mustafar, 2005, "Kajian jaringan kawalan pugak bagi Negeri Sarawak" MSc Thesis, Faculty of Geoinformation Science \& Engineering, UTM Skudai.

Zainal Abidin Md Som \& Anual Aziz, 2006 "The adjustment of regional leveling network using an in-house developed software." Paper presented at the International Symposium \& Exhibition on Geoinformation, Shah Alam. 